\title{
Transgenic microalgae as a non-antibiotic bactericide producer to defend against bacterial pathogen infection in the fish digestive tract
}

\author{
Si-Shen Li ${ }^{1}$, Huai-Jen Tsai* \\ Institute of Molecular and Cellular Biology, National Taiwan University, No. 1, Section 4, Roosevelt Road, Taipei 106, Taiwan
}

\section{A R T I C L E I N F O}

\section{Article history:}

Received 21 September 2007

Received in revised form 12 July 2008

Accepted 12 July 2008

Available online 19 July 2008

\section{Keywords:}

Defense

Fish

Lactoferricin

Microalgae

Transgenesis

Vibrio

\begin{abstract}
A B S T R A C T
Antibiotics are commonly employed in most fish aquacultures to prevent disease. One major risk in this practice is that antibiotic-resistant pathogens may be selected. Therefore, we wanted to examine the feasibility of producing an economical, non-antibiotic alternative. The microalga Nannochloropsis oculata is an essential phytoplankton used as live feed for fish larvae. We attempted to culture N. oculata in a way that would provide an organism against bacterial pathogenic infection. To test this idea, we constructed an algae-codon-optimized bovine lactoferricin (LFB) fused with a red fluorescent protein (DsRed) driven by a heat-inducible promoter, which is a heat shock protein $70 \mathrm{~A}$ promoter combined with a ribulose-1,5bisphosphate carboxylase/oxygenase small subunit $2^{\prime}$ promoter from Chlamydomonas reinhardtii. After electroporation, we examined 491 microalgal clones and generated two stable transgenic lines, each expressing a stable transgene inheritance for at least 26 months. This was confirmed by the positive detection of the mRNA transcript and the protein of LFB-DsRed produced by the transgenic microalgae. To test the efficacy of the antimicrobial peptide LFB, medaka fish (Oryzias latipes) were adapted from freshwater to seawater and were fed with the transgenic algae by oral-in-tube delivery method. Bacterial infection with $1 \times 10^{5}$ Vibrio parahaemolyticus per fish was induced $6 \mathrm{~h}$ thereafter by oral-in-tube delivery as well. For medaka fish fed with $1 \times 10^{8}$ transgenic algae per fish, the average survival rate after a 24 -h period of infection was much higher than that of medaka fed with wild-type algae $(85 \pm 7.1 \%$ versus $5 \pm 7.1 \%$ ). This result suggests that medaka fish fed with the LFB-containing transgenic microalgae will have bactericidal defense against $V$. parahaemolyticus infection in its digestive tract.
\end{abstract}

(c) 2008 Elsevier Ltd. All rights reserved.

\section{Introduction}

As a key cost-saving step, antibiotics are commonly employed in most fish aquacultures to prevent disease. However, the risk in this practice is that antibiotic-resistant pathogens may be selected and spread out along with the wastewater to cause serious environmental pollution. To address this problem, we attempt to develop a safer, more effective and less expensive biological bactericide for aquaculture use.

Bovine lactoferricin (LFB) is a 3142-Da peptide derived from the $\mathrm{N}$ terminus of bovine lactoferrin (from Phe17 to Phe41). LFB can be generated by pepsin hydrolysis in the digestive tract [1]. LFB is an antimicrobial peptide that can kill or inactivate many pathogens, including Gram negative bacteria such as Escherichia coli [1], Klebsiella pneumoniae [2], Proteus vulgaris [3] and Pseudomonas aeruginosa [2]; Gram positive bacteria such as Clostridium paraputrificum, Corynebacterium ammoniagenes, Enterococcus faecalis

\footnotetext{
* Corresponding author. Tel.: +886 23366 2487; fax: +886 223638483. E-mail address: hjtsai@ntu.edu.tw (H.-J. Tsai).

1 Present address: Taiwan Ocean Research Institute, Taipei, Tawian.
}

[4], Listeria monocytogenes [1] and Streptococcus bovis [2]; parasites such as Eimeria stiedai [5], Giardia lamblia [6], and Toxoplasma gondii [7]; fungi such as Aspergillus fumigatus; and viruses such as adenovirus [8], calicivirus [9] and cytomegalovirus [10]. Since LFB can suppress a wide variety of pathogens, it is an excellent antimicrobial peptide for aquaculture application. At the same time, LFB can only be produced by the hydrolysis of bovine lactoferrin under pepsin treatment in native source [11]. However, as described below, we are able to bypass this limitation by creating conditions by which microalgae can generate LFB.

Microalgae have many advantages as bioreactors for the production of heterologous proteins. First, microalgae can produce complicated eukaryotic proteins after post-translational modification [12]. Second, although microalgae are eukaryotic, they can be cultured rapidly and economically. Third, microalgae are considered as a safe food because they are free from human pathogens and endotoxins [13].

In this study, we have used Nannochloropsis oculata, a marine unicellular microalga which belongs to the class of Eustigmatophyceae and which has a spherical or slightly ovoid shape of about $2-4 \mu \mathrm{m}$ in diameter. This microalga consists of a polysaccharide wall and contains only one chloroplast [14]. Because $N$. oculata 
grows in a wide range of saline concentrations and contains a high amount of eicosapentaenoic acid [15], it is an important phytoplankton in the diet of fish larvae and an important organism for making 'green water' aquaculture ponds [16]. In addition to the above advantages, $N$. oculata can be cultured in a closed system along the seashore and in the sea pond, thus eliminating the need for scarce freshwater and otherwise tillable land. Unlike yeast and cell line cultures, expensive medium and aseptic manipulation of $N$. oculata are not required. Moreover, as noted above, $N$. oculata can survive under extreme saline conditions; consequently, it can be grown in both freshwater and seawater aquaculture. Lastly, since the cryopreservation technique for $N$. oculata has been well developed, transgenic $N$. oculata is already available $[17,18]$.

In this study, we screened a stable transgenic line of $N$. oculata which has bactericidal activity. By feeding this transgenic $N$. oculata to a small model fish, medaka, we observed a significant increase in the survival rate $24 \mathrm{~h}$ after bacterial pathogenic infection with Vibrio parahaemolyticus in the fish digestive tract.

\section{Materials and methods}

\subsection{Plasmid construction and preparation}

An inducible promoter of algae expression vector, Hsp70A plus RBCS 2, was obtained by cutting NheI and EcoRV from pCB740 [19]. A cDNA of fusion protein, an algae-codon-optimized [20] LFB, which was fused with a DsRed reporter and driven by this inducible promoter, was generated by the following sequential PCR. Plasmid pDsRed 2-1 (Clontech) containing the DsRed cDNA of Discosoma sp. was used as a template. Three forward primers and one reverse primer were designed: CF3 (GCTAGCACCGGTCGCCACCATGTTCAA ATGTCGTCGTTGGCAATGGCGT), containing an Nhel cutting site and a 19-bp Kozak sequence; CF2 (GCAATGGCGTATGAAAAAATTAGGT GCTCCTTCTATTAC), containing a 78-bp algae-codon-optimized LFB cDNA and two pepsin-digestion sites, and CF1 (CTTCTATTACATGT GTACGTCGTGCTTTCATGGCCTCCT), containing the partial cDNA of N terminus (10 bp) of DsRed; one reverse primer, CR (ATTTGTGATGC TATTGCTTTATTTGTAACCATT), containing partial cDNA of $C$ terminus (10 bp) of DsRed and an EcoRV cutting site. Primers CF1 and CR were used in the first PCR reaction under the following conditions: 5 cycles of denaturation at $94{ }^{\circ} \mathrm{C}$ for $30 \mathrm{~s}$, annealing at $30{ }^{\circ} \mathrm{C}$ for $15 \mathrm{~s}$ and extension at $72{ }^{\circ} \mathrm{C}$ for $90 \mathrm{~s}$, followed by 20 cycles of denaturation at $94{ }^{\circ} \mathrm{C}$ for $30 \mathrm{~s}$, annealing at $60^{\circ} \mathrm{C}$ for $15 \mathrm{~s}$ and extension at $72{ }^{\circ} \mathrm{C}$ for $90 \mathrm{~s}$. The resultant 734-bp PCR product was extracted from a $2 \%$ agarose gel after electrophoresis. This PCR product was used as the template DNA for the second PCR reaction using primers CF2 and CR. The resultant 763-bp PCR product was used as the template for the third PCR reaction by using primers CF3 and CR. The final 802-bp PCR product was cloned into plasmid pGEM-T easy. After the resultant plasmid was digested with NheI and EcoRV, it was inserted into the NheI-EcoRV cut of pCB740 to generate the algal LFB expression plasmid, phr-rLFB-Red. This plasmid was linearized by SacII and readied for gene transfer use.

\subsection{Culture conditions and synthetic gastric juice treatment of microalgae}

$N$. oculata cells obtained from Taiwan Fisheries Research Institute were cultured in $\mathrm{f} / 2$ medium [21] at $28^{\circ} \mathrm{C}$ with an illumination of white fluorescent tubes (Taiwan Fluorescence Company: FL40D/ 38 ) on a $12: 12 \mathrm{~h} \mathrm{light/day} \mathrm{cycle.} \mathrm{For} \mathrm{preparing} \mathrm{protoplasts,} 5 \mathrm{ml}$ of $N$. oculata cells $\left(1 \times 10^{7}\right.$ cells $\left.\mathrm{ml}^{-1}\right)$ were collected by centrifugation at $8000 \times \mathrm{g}$ for $10 \mathrm{~min}$ at $4{ }^{\circ} \mathrm{C}$. The pellet was washed twice with $1 \mathrm{ml}$ of sterilized seawater, resuspended in $500 \mu \mathrm{l}$ of synthetic gastric juice [22], and incubated at $37{ }^{\circ} \mathrm{C}$ for different times in the dark with gentle shaking. After treatment, cells were washed twice with $1 \mathrm{ml}$ of sterilized seawater to terminate enzymatic activity and observed by microscope. Finally, the pellet was resuspended in $0.2 \mathrm{ml}$ electroporation buffer [23] and chilled on ice for $10 \mathrm{~min}$ to prepare for electroporation.

\subsection{Gene transfer by electroporation}

One half $(0.1 \mathrm{ml})$ of $N$. oculata protoplasts resuspended in the electroporation buffer was added to $10 \mu \mathrm{g}$ of SacIl-restricted phrrLFB-Red. Then, the gene transfer was performed by electroporator (ECM 2001, BTX, USA) under various voltages ranging from 1 to $2 \mathrm{kV}$ at $20 \mu$ s pulse time for 10 pulses to generate the transgenic N. oculata.

\subsection{Regeneration and growth}

After electroporation, $N$. oculata cells were transferred to a glass tube containing $1 \mathrm{ml}$ of fresh $\mathrm{f} / 2$ medium and cultured at $28^{\circ} \mathrm{C}$ for $24 \mathrm{~h}$ with agitation at $200 \mathrm{rpm}$. Twenty microlitres of algal cells grown at log phase $\left(1 \times 10^{7}\right.$ cells ml $\left.{ }^{-1}\right)$ were spread on an agar plate containing f $/ 2$ medium and incubated at $28^{\circ} \mathrm{C}$ for 5-7 days. Colonies were picked up and cultured in liquid medium as described above for subsequent analysis.

\subsection{Genomic DNA extraction}

The genomic DNA extraction of $N$. oculata followed the description of Dawson et al. [24] with some modifications. Microalgal cells were harvested from $5 \mathrm{ml}$ (approximately $1 \times 10^{7}$ cells $\mathrm{ml}^{-1}$ ) of culture medium and resuspended in $500 \mu \mathrm{l}$ of buffer solution ( $54 \mathrm{mM}$ hexadecyltrimethylammonium bromide, 0.25 $\mathrm{mM}$ Tris (pH 8.0), $1.4 \mathrm{M} \mathrm{NaCl}, 10 \mathrm{mM}$ EDTA, and $2 \% \beta$-mercaptoethanol). The mixture was incubated at $65{ }^{\circ} \mathrm{C}$ for $2 \mathrm{~h}$ and shaken every $15 \mathrm{~min}$. After incubation, an equal volume of phenolchloroform was added, and the aqueous phase was recovered after 5 min of centrifugation at $8000 \times g$ at $25^{\circ} \mathrm{C}$ for $10 \mathrm{~min}$. We extracted several times until the aqueous layer was no longer cloudy. The genomic DNA was precipitated with two volumes of $100 \%$ ethanol, centrifuged at $8000 \times g$ for 15 min, washed with $70 \%$ ethanol, dried, and resuspended in $30 \mu \mathrm{l}$ of TE buffer.

\subsection{Screening the putative transgenic N. oculata by PCR analysis}

Two oligonucleotide primers were synthesized for detection of the existence of the transferred DNA fragment, DsRed cDNA, by PCR analysis: a forward primer (DF: CCTCCTCCGAGAACGTCATCACC GAG) and a reverse primer (DR: CCTCGGTGCGCTCGTACTGCT). The primers for detection of the endogenous 18S rRNA gene, which served as an internal control, were forward primer (GCGGAGGA AAAGAACTAACCAGGATT) and reverse primer (AACGCCATGGCACA CCGC). Each PCR sample consisted of $20 \mu \mathrm{l}$ of solution containing $10-20 \mathrm{ng}$ of template, $10 \mathrm{pmol}$ of each primer, $25 \mu \mathrm{M}$ of each dNTP, and 5 units of Taq enzyme (Viotech, Taiwan) in a $10 \times$ PCR buffer. Amplification was performed with a Perkin-Elmer Cetus DNA Thermal Cycler (USA). PCR consisted of 25 cycles of denaturation at $94{ }^{\circ} \mathrm{C}$ for $1 \mathrm{~min}$, annealing at $55^{\circ} \mathrm{C}$ for $1 \mathrm{~min}$, and extension at $72{ }^{\circ} \mathrm{C}$ for $1 \mathrm{~min}$, followed by $10 \mathrm{~min}$ extension at $72{ }^{\circ} \mathrm{C}$. PCR products $(10 \mu \mathrm{l})$ were subjected to electrophoresis on a $3 \%$ NuSieve GTG agarose gel (FMC BioProducts, USA).

\subsection{Screening the putative transgenic $N$. oculata by fluorescent microscope}

In addition to using PCR to screen the putative transgenic clones of microalgae, we also used fluorescent microscopy to detect the transgenic clones because the transgene contains DsRed. After 
electroporation, we cultured microalgae on agar plates for two months and observed the expression of red fluorescence at $610 \mathrm{~nm}$ under a stereo dissecting microscope (MZ12, Leica) equipped with a fluorescent module having a DsRed filter cube (Kramer Scientific Corp., Valley Cottage, NY, USA).

\subsection{Preparation of $m R N A$}

After $40 \mathrm{ml}$ of wild type and transgenic microalgae $\left(1 \times 10^{7}\right.$ cells $\mathrm{ml}^{-1}$ ) were treated at $42^{\circ} \mathrm{C}$ for $16 \mathrm{~h}$, microalgal cells were harvested from culture medium and resuspended in $1 \mathrm{ml}$ of REzol reagent (PeproTech, Rocky Hill, NJ, USA). The mixture was shaken for $30 \mathrm{~s}$ and incubated at $25{ }^{\circ} \mathrm{C}$ for $5 \mathrm{~min}$. After incubation, $200 \mu \mathrm{l}$ of phenol-chloroform were added, and the aqueous phase was recovered after $5 \mathrm{~min}$ of centrifugation at $8000 \times \mathrm{g}$ at $4{ }^{\circ} \mathrm{C}$ for $10 \mathrm{~min}$ and the DNA was digested by DNase at $37^{\circ} \mathrm{C}$ for $1 \mathrm{~h}$. The mRNA was precipitated with 0.6 volume of isopropanol, incubated for $2 \mathrm{~h}$, centrifuged at $8000 \times \mathrm{g}$ for $15 \mathrm{~min}$ at $4{ }^{\circ} \mathrm{C}$, and, finally, washed with $70 \%$ ethanol, dried, and resuspended in $30 \mu \mathrm{l}$ of DEPC water.

\subsection{Reverse transcription-polymerase chain reaction (RT-PCR)}

First-strand cDNA was synthesized using the SuperScript II Preamplification System (Gibco BRL). Primers LF and LR were used to amplify an expected 68-bp PCR product from the transcript of LFB cDNA. Primers PF (CGCTGAGGCTTGACATGATTGGTG) and LR (GCCATGAAAGCACGTACACATGTAAT) were used to amplify a 380bp PCR fragment from the contaminated plasmid DNA which is not eliminated by DNase. If the 380-bp PCR fragment did not appear, the results of algal transcriptional experiments were authentic.

\subsection{Induction, protein extraction and western blot analysis}

Fifty millilitres (about $1 \times 10^{7}$ cells $\mathrm{ml}^{-1}$ ) of the transformed $N$. oculata were treated by shifting to $42{ }^{\circ} \mathrm{C}$ for $16 \mathrm{~h}$ to express the exogenous protein driven by an inducible promoter of Hsp70A and RBCS 2. After induction, the total proteins were extracted from the transgenic $N$. oculata using the protocol of Hawkins and Nakamura [25] with a modification. Briefly, after microalgae were collected by centrifuging for $10 \mathrm{~min}$ at $8000 \times \mathrm{g}$ at $4{ }^{\circ} \mathrm{C}$, the pellet was resuspended in $500 \mu$ l of extraction buffer [26]. The cell suspension was transferred to a microtube (Axygen Scientific, USA) containing $0.5 \mathrm{~g}$ of glass beads (Sigma, USA) and broken by a mini-bead beater (BioSpec Products, Bartlesville, OK, USA) at room temperature for $30 \mathrm{~s}$ with a $90 \mathrm{~s}$ interval on ice, a process repeated for 15 times. The supernatant was centrifuged for $15 \mathrm{~min}$ at $10,000 \times \mathrm{g}$ at $4{ }^{\circ} \mathrm{C}$, and $50 \mu$ of sample loading buffer ( $1 \mathrm{mM}$ EDTA, $250 \mathrm{mM}$ Tris- $\mathrm{HCl}(\mathrm{pH}$ 6.8), 4\% SDS, $2 \% \beta$-mercaptoethanol, $0.2 \%$ bromophenol blue, $50 \%$ glycerol) was added to dissolve the pellet. Prior to SDS-PAGE analysis, samples were boiled for $40 \mathrm{~min}$ and then centrifuged for $5 \mathrm{~min}$ at $10,000 \times g$. The supernatant was electrophoresed on a $12 \%$ SDSpolyacrylamide gel. A mouse monoclonal antibody against DsRed (Clontech, USA) was used to detect the recombinant fusion protein of LFB-DsRed. The final dilution of monoclonal antibody was $1: 2000$, and an alkaline phosphatase-conjugated anti-rabbit IgG (Santa Cruz, USA) was used as the secondary antibody. The procedures for western blot analysis were described previously [27].

\subsection{Bactericidal activity of recombinant LFB produced} by transgenic N. oculata

To detect the efficacy of bactericidal activity of recombinant LFB produced by the transgenic microalgae that we cloned, we performed a filter paper disc assay. Different volumes of microalgae were treated by synthetic gastric juice for $4 \mathrm{~h}$, spotted on a paper disc $(0.5 \mathrm{~cm}$ at diameter), placed on a covered agar plate containing $V$. parahaemolyticus and cultured at $37^{\circ} \mathrm{C}$ for $16 \mathrm{~h}$. This in vitro inhibition zone assay was performed three times. For in vivo bioassay, the small model freshwater fish, Japanese medaka (Oryzias latipes), which had been adapted from freshwater to seawater seven days prior, was used. Then, we delivered either wild type or transgenic algae into the stomach of medaka in different amounts $\left(1 \times 10^{6}\right.$ or $1 \times 10^{8}$ cells per fish) by tomcat catheter tube through the mouth. After oral-in-tube delivery of algae for $6 \mathrm{~h}$, both wild type and transgenic medaka were infected with $V$. parahaemolyticus, again using oral-in-tube delivery. The survival rate of microalgae-treated medaka was calculated $24 \mathrm{~h}$ after $V$. parahaemolyticus transfection. This in vivo assay was performed by two independent trials.

\section{Results}

\subsection{Plasmid construction}

Four primers (CF1-CF4) were used to obtain various PCR products from pDsRed 2-1 (Clontech) as a template. The nucleic acid sequence of each PCR product was confirmed by DNA sequencing. The final plasmid of phr-rLFB-DsRed with a molecular mass of $4.4 \mathrm{~kb}$ was constructed with a Kozak consensus sequence consisting of a 78-bp algae-codon-optimized LFB peptide, including two pepsin-digestion sites at Phe2-Lys and Phe26-Met and a DsRed protein (Fig. 1). This fusion protein was driven by a promoter of HSP70A combined with RBCS 2 from Chlamydomonas reinhardtii.

\subsection{Preparation of the protoplasts of $N$. oculata for gene transfer}

After $N$. oculata cells were cultured at log phase to a density of $1 \times 10^{7}$ cells, we treated them with synthetic gastric juice [22] and gentle shaking at $37^{\circ} \mathrm{C}$ for $0,30,60,120$ and 240 min in the dark. The number of intact algae cells decreased as the time of synthetic gastric acid treatment increased (Fig. 2). Thus, when synthetic gastric acid was treated for $0,10,30,60,120$ and $240 \mathrm{~min}$, a total of 147, 20, 8, 4, 0 and 0 algal cells remained intact, respectively. We took algal protoplasts after treating for $30 \mathrm{~min}$ with synthetic gastric juice and electroporated in the presence of SacII-cut phrrLFB-DsRed for $20 \mu$ s pulse time and 10 pulses, either at 1 or at $2 \mathrm{kV}$. There were 1248 and 147 clones to generate the transgenic $N$. oculata, respectively. We also prepared protoplasts from the algae that were treated with gastric juice for $60 \mathrm{~min} ; 24$ and 21 algal clones survived after they were electroporated in the presence of SacII-cut phr-rLFB-DsRed for $20 \mu$ s pulse time and 10 pulses, either at 1 or $2 \mathrm{kV}$, respectively.

\subsection{Screening the putative transgenic clones of N. oculata by PCR}

Since antibiotics did not affect the growth of microalgae in solid plate culture, $N$. oculata cells were observed to grow normally in the medium, whether or not the cells contained the plasmid phr-rLFBRed. Thus, in order to identify if each colony contained the transferred gene after electroporation and culturing at the third generation, we used PCR. The primers DF and DR were used to carry out the PCR amplification for screening of microalgae harboring phr-rLFB-Red (Fig. 1). In total, we screened 491 transformants grown on the culture plates. These transformants were randomly selected from the group which had been electroporated at $1 \mathrm{kV}$ and treated with gastric juice for either 30 or 60 min. As expected, a single 450 -bp PCR product was generated for the samples from either the $30 \mathrm{~min}$ group (Fig. 3A, left lanes $1,6-9$ ) or the 60 min group (Fig. 3A, right lanes 4-6, 8 and 9) when the primers DF and DR were used.

The molecular mass of this positive band was similar to that of the PCR product amplified from the DNA fragment, a SacII-cut 


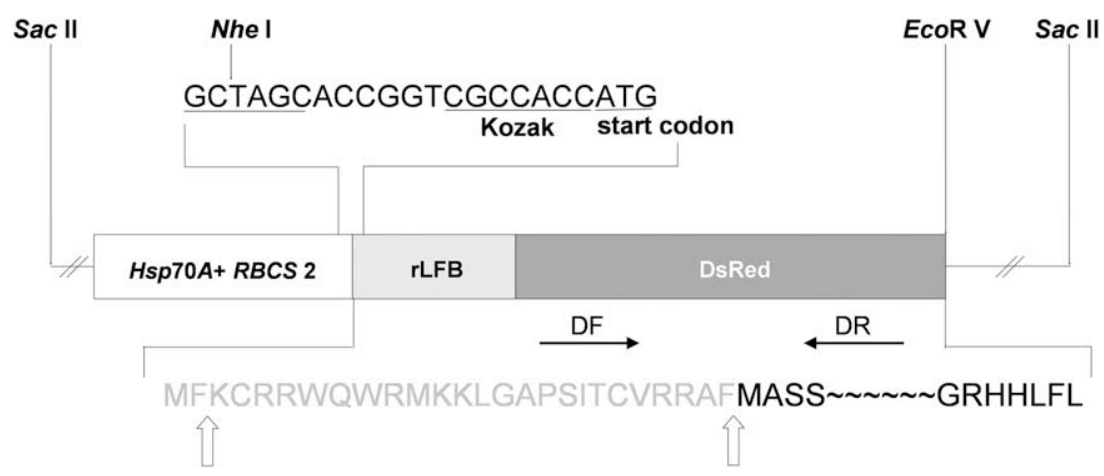

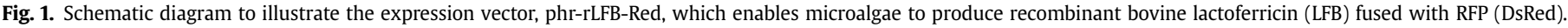

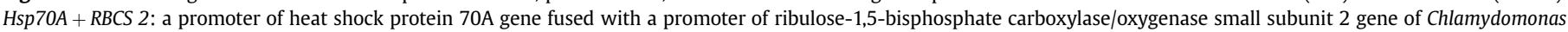

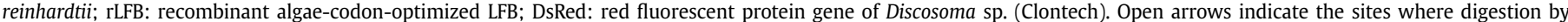

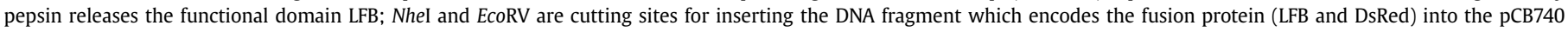
vector. DF and DR are the primers used for screening of microalgal transformants harboring phr-rLFB-Red. A 450-bp PCR product is expected to amplify.

phr-rLFB-DsRed DNA, which was used for gene transfer. The significance of the similarity lies in the fact that the foreign DNA fragments had been transferred into microalgae. However, we noticed that although more than $50 \%$ of examined clones harbored the transferred DNA fragment from the microalgae electroporated at $1 \mathrm{kV}$, almost every clone harbored the transferred gene from the microalgae electroporated at $2 \mathrm{kV}$ (Fig. 3B). At the same time, however, most of these transformants completely lost their exogenous DNA fragment when we examined them after culturing for 15 months, suggesting that the transgene is not stably inherited in most $N$. oculata after a long period of culture. After intensive screening, we only find two PCRpositive clones after they have been cultured for 22 months, and these were designated as stable lines 0829A and 0829B. In spite of low possibility of obtaining a stable line, one still has a chance to discover stable transgenic strain after massive screening.
Interestingly, when the transgenic microalgae grew on agar plates more than 60 days, fluorescence microscopy detected a predominant red fluorescent signal, but only around the colonies of stable lines 0829A and 0829B (Fig. 4A, D and E). Both signals were so strong that $0829 \mathrm{~A}$ and $0829 \mathrm{~B}$ could be observed by viable light under photomicroscope (Fig. 4A), but since the signal of 0829A was stronger than 0829B, we chose stable line 0829A for further experiments.

\subsection{Using reverse transcription-polymerase chain reaction (RT-PCR) to detect the transcript of transgene}

RT-PCR was used to analyze the RNAs extracted from $20 \mathrm{ml}$ PCRpositive microalgae $\left(1 \times 10^{7}\right.$ cells ml $\left.{ }^{-1}\right)$ at third generation after they were induced at $42{ }^{\circ} \mathrm{C}$ for $16 \mathrm{~h}$. Primers LF and LR were designed to amplify an expected 68-bp DNA fragment from the
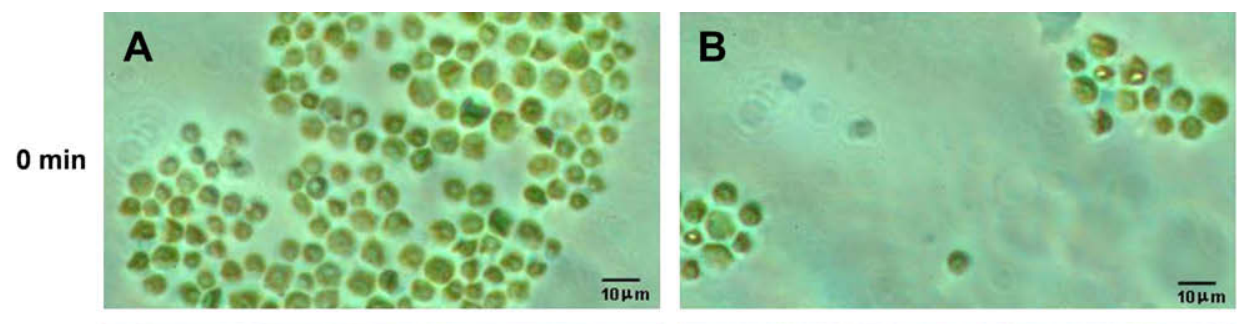

$10 \mathrm{~min}$
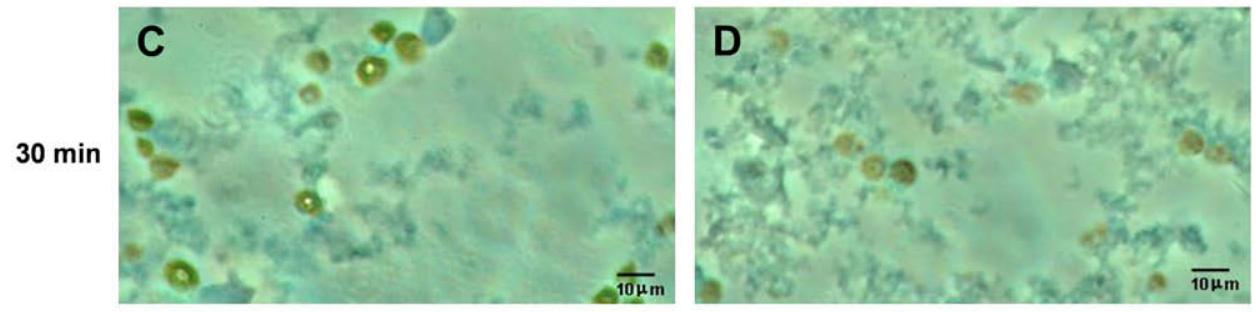

$60 \mathrm{~min}$
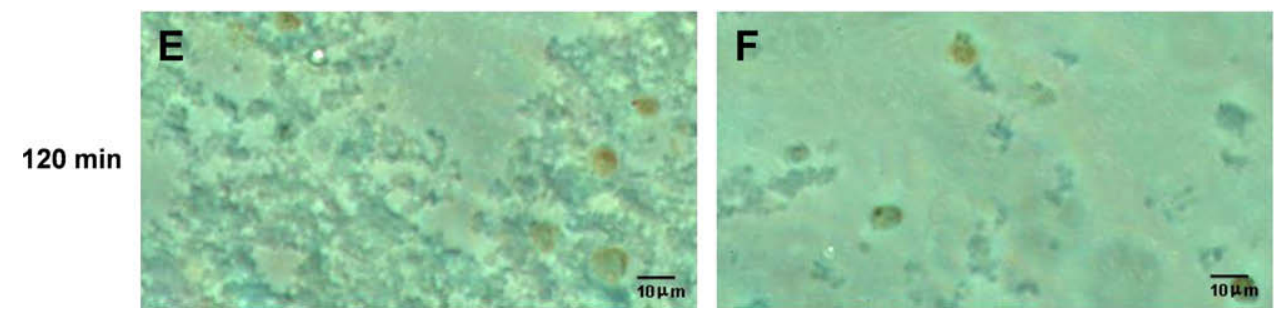

$240 \mathrm{~min}$

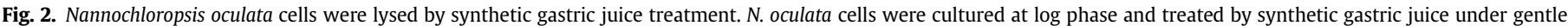
shaking at $37^{\circ} \mathrm{C}$ in the dark for certain times as indicated. The number of intact algal cells decreased when the time of synthetic gastric acid treatment increased. 

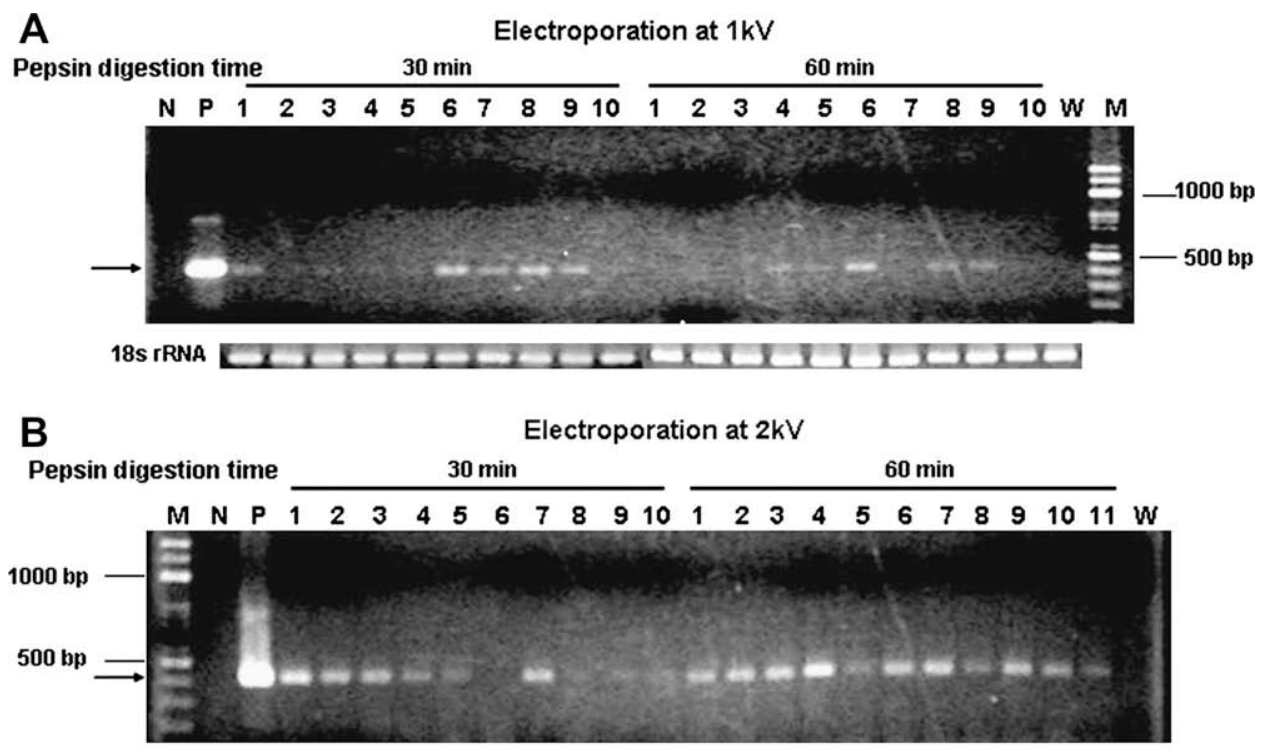

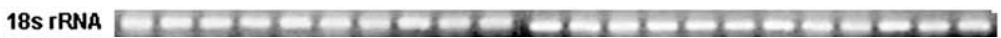

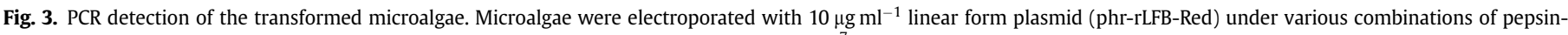

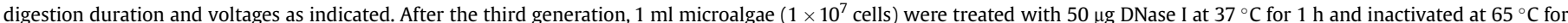

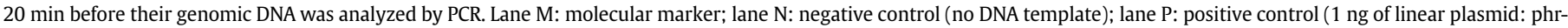

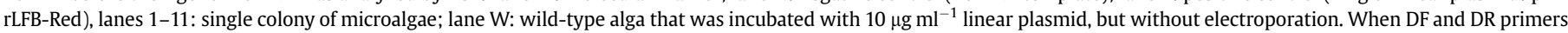
were used, a 450-bp PCR product was expected to be produced by transgenic microalgae. Amplification of $18 \mathrm{~S}$ rRNA served as an internal control.

transcripts of LFB cDNA, whereas primers PF and LR were designed to amplify an expected 380-bp DNA fragment from the contaminated plasmid DNA, which included the promoter (Fig. 5A). Results showed that three transgenic microalgae displayed a 68-bp PCR product, indicating that the LFB-DsRed fusion gene could be transcribed from the transgene SacII-cut phr-rLFB-DsRed (Fig. 5B).

\subsection{Protein and western blot analyses}

After treating the transgenic line $0829 \mathrm{~A}$ microalga at $42^{\circ} \mathrm{C}$ for $16 \mathrm{~h}$, the total proteins were extracted and analyzed by SDS-polyacrylamide gel electrophoresis. Results showed that an extra peptide band with molecular mass of about $100 \mathrm{kDa}$ was expressed in the transgenic microalgal line, which was absent in the proteins extracted from the wild type (Fig. 6A). This 100-kDa-protein band, which corresponded to the tetramer of fusion protein LFB-DsRed, was positive for immunological detection when analyzed by western blotting using mouse monoclonal antibody against DsRed (Fig. 6B). We also noticed that only a small amount of fusion protein was expressed before heat shock treatment (Fig. 6B), suggesting that the promoter of $H S P 70 A$ combined with RBCS 2 from $C$. reinhardtii is not tightly controlled, as previously reported [19].

\subsection{Bactericidal activity of recombinant LFB produced by transgenic $N$. oculata}

The transgenic alga 0829A was cultured at log phase, induced by heat shock, and the cells were harvested and resuspended in gastric acid for $4 \mathrm{~h}$. Cell lysate was obtained, spotted on the disc and placed on an agar plate containing $V$. parahaemolyticus. An inhibition zone with a diameter of $5 \mathrm{~mm}$ occurred if the lysate was extracted from a $25 \mathrm{ml}$ culture (Fig. 7). Compared to the potency of Ampicillin on the same plate, the bactericidal efficacy of lysate from a $25 \mathrm{ml}$ culture of transgenic alga line 0829A was equivalent to $8.9 \pm 0.66 \mu \mathrm{g}$, an average of three times that of Ampicillin, which was $0.356 \pm 0.026 \mu \mathrm{g}$ Ampicillin per ml (or $3.56 \pm 0.26 \times 10^{-8} \mu \mathrm{g}$ Ampicillin per cell). The inhibition zone on the filter paper disc assay was also observed in the lysate extracted from $5 \mathrm{ml}$ transgenic microalga, but neither in the lysate extracted from $1 \mathrm{ml}$ transgenic microalga nor in the lysate extracted from $25 \mathrm{ml}$ wildtype algae (Fig. 8), which indicates that bactericidal activity could be achieved from a large amount of the lactoferricin-containing transgenic microalgal line 0829A.

To determine the bactericidal potency of transgenic microalga 0828A in vivo, we employed medaka fish which had been adapted from freshwater to seawater during the previous five days. Regarding the lethal condition of infection of medaka by $V$. parahaemolyticus, we found that the oral delivery of $1 \times 10^{5} \mathrm{~V}$. parahaemolyticus killed a medaka fish within $24 \mathrm{~h}$. And, after oral delivery of $1 \times 10^{8}$ transgenic microalgae per fish after $6 \mathrm{~h}$ enabled medaka to completely protect from the infection of $1 \times 10^{5}$ of $V$. parahaemolyticus.

To test for dose dependency, we fed medaka by the oral-in-tube method either $1 \times 10^{6}$ or $1 \times 10^{8}$ microalgae per fish. Six hours thereafter, $V$. parahaemolyticus infection was induced orally by either a high $\left(1 \times 10^{5}\right.$ cells per fish $)$ or a low $\left(1 \times 10^{4}\right.$ cells per fish $)$ dosage. Results showed that the survival rate of medaka fed with $1 \times 10^{8}$ transgenic algae per fish and then infected with $1 \times 10^{5}$ Vibrio cells per fish was significantly higher than that of medaka fed with the same dosage of wild-type algae and infected by same dosage of Vibrio: $85 \pm 7.1 \%$ versus $5 \pm 7.1 \%$ (Table 1 ). This result was also consistent with fish fed with a lower dosage $\left(1 \times 10^{6}\right)$ of transgenic algae per fish and then infected with $1 \times 10^{5}$ Vibrio cells per fish: $70 \%$ versus $5 \pm 7.1 \%$ (Table 1 ). The enhancement of survival of medaka after same strategy of $V$. parahaemolyticus infection was also concluded from the results of medaka fish infected with only one-tenth the dosage $\left(1 \times 10^{4}\right.$ cells per fish) of $V$. parahaemolyticus. All of this evidence indicates the protective efficacy of transgenic microalga against Vibrio-infected fish.

\section{Discussion}

\subsection{Plasmid design}

LFB is an antimicrobial peptide which can kill or inactivate many kinds of pathogens. In order to use LFB conveniently, the expression 

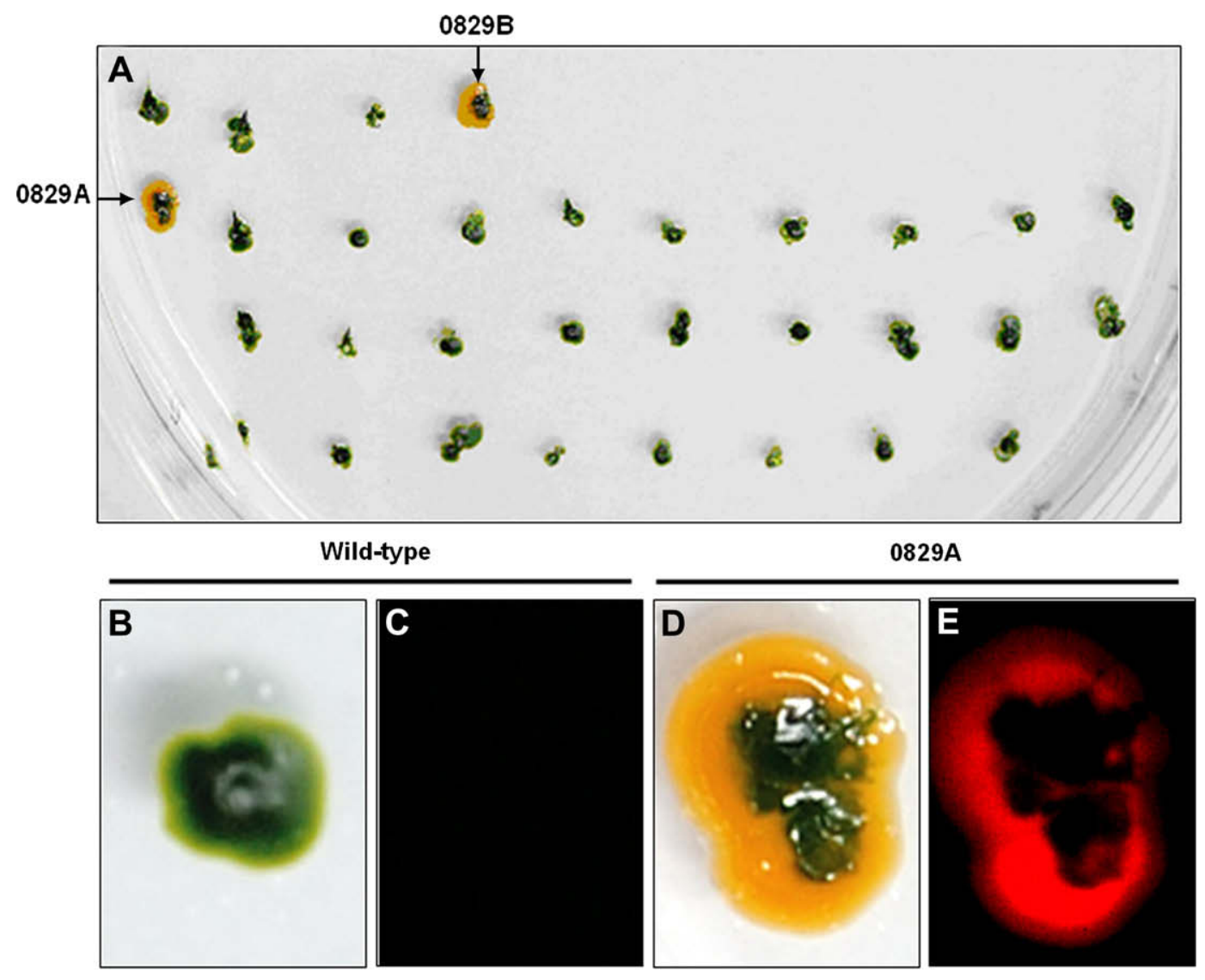

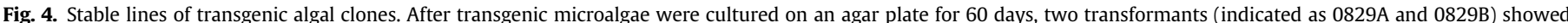

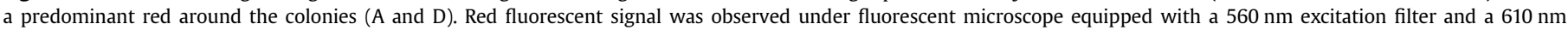

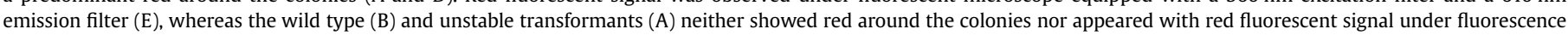
microscopy (C). (For interpretation of the references to colour in this figure legend, the reader is referred to the web version of this article.)

systems of $E$. coli and yeast used to produce recombinant LFB have been well developed. This has resulted in a bactericidal efficacy of this artificial LFB very similar to that of native LFB [28-30]. However, it is not practical to produce this type of artificial LFB because of the high cost of medium or isopropyl-beta-D-thiogalactopyranoside (IPTG). Moreover, while the bactericidal ability of LFB has the desirable effect of killing or inactivating pathogens, it can also negatively affect the host cells, $E$. coli and yeast which produce it [28-30]. In order to overcome this particular disadvantage, the bioengineered LFB produced by $E$. coli and yeast is designed to create a non-bactericidal form. After purification, separation, enzyme digestion and fragmentation the functional LFB is finally obtained. However, these steps only add to the overall cost of producing artificial LFB. Meanwhile, there remains the additional possibility of generating a resistant strain against LFB [31] when artificial LFB is applied on a large scale, especially in aquatic ponds.

To address these questions and, at the same time, reduce the risks, we designed a fusion protein, LFB-DsRed, that contains a pepsin cutting site located at Phe2-Lys and Phe26-Met, where the junction between LFB and DsRed is located. Using this fusion protein, after pepsin digestion by a pathogen, the functional LFB is released into an extremely acidic environment, much like the gastrointestinal environment in which native LFB is released from bovine lactoferrin in the digestive tract $[11,32]$. By this strategy, we have both avoided the damage caused by LFB to the host cells and prevented the conditions otherwise required for the LFB-resistant pathogenic strains to spread out in the natural environment. In other words, the functional LFB is restricted to the digestive tract so that LFB-resistant pathogens are strictly confined in the extremely acidic environment where the functional LFB exists. This extreme environment is not suitable for most bacteria; therefore, even if LFB-resistant pathogens were generated, they would not be able to survive very long in the general environment or compete with other microorganisms which have made an adaptation to a non-acidic environment.

\subsection{Transgenic system}

In order to decrease production costs and enhance the operational efficiency of LFB in aquaculture, we use the microalga $N$. oculata, which is commonly used in marine aquaculture, to produce the LFB. Although transgenic technology of $N$. oculata is not yet perfected, some methods of algal transformation have been developed over the last 20 years, including bombardment [25], polyethylene glycol method [33], glass-bead method [34] and electroporation [23]. With electroporation, it is easy to transfer DNA into small organisms with low operational costs. It allows manipulation of a large number of samples at one trial, which is quite useful for small and numerous organisms, such as microalgae. On the other hand, because the poly-layer structure of cell wall [35] might also hinder the efficiency of gene transfer into $N$. oculata, we treated $N$. oculata with synthetic gastric juice [22], which contains pepsin, to digest the cell wall before electroporation. Thus, in the case where electroporation is performed at $2 \mathrm{kV}$ in $20 \mu$ s pulse time for 10 pulses, the transgenic rate can reach as high as $100 \%$ in the parental generation if a $10 \mu \mathrm{g}$ linear form of plasmid DNA is employed (Fig. 3). As a result, this approach made it possible for us 
A

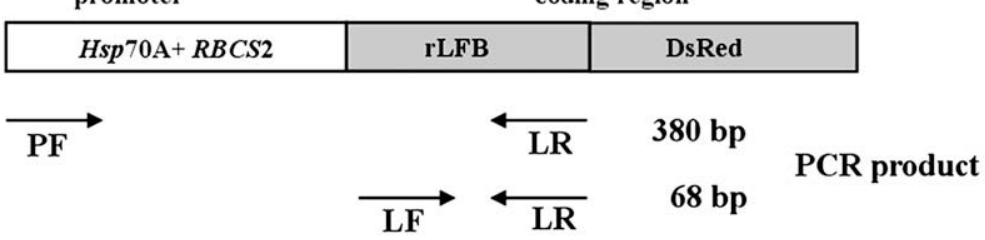

B

Primer set

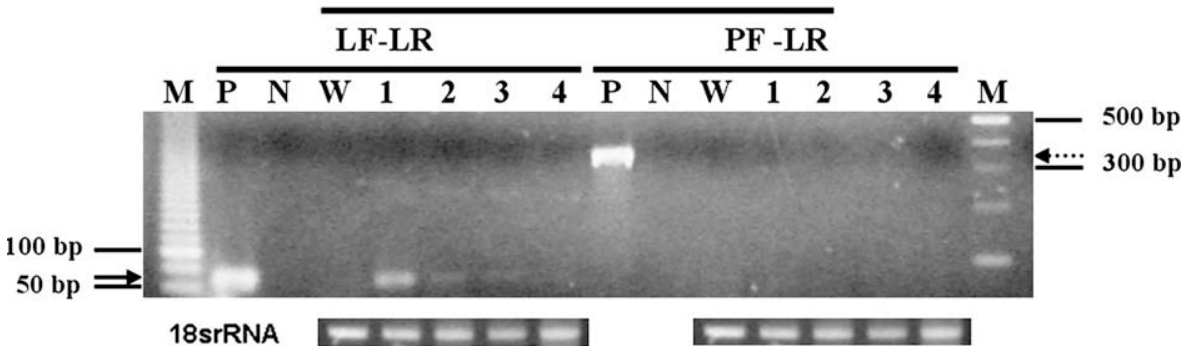

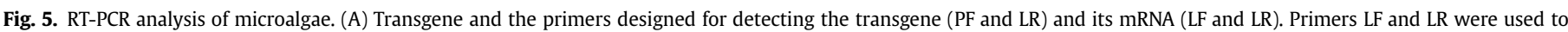

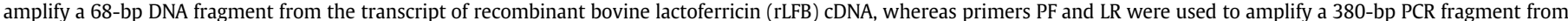

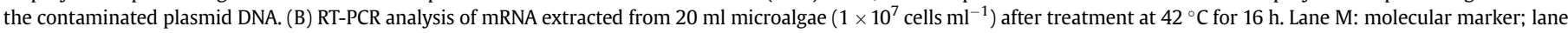

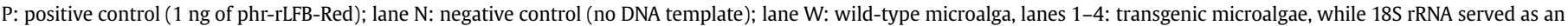
internal control.

to use electroporation for those microalgae that lacked cell-wall mutants.

Following that strategy in the present study, after we had subcultured the resultant clones for a period of three months, two stable lines of transgenic $N$. oculata, termed 0829A and 0829B, were screened. Out of 491 microalgal clones, these two transgenic lines each displayed a stable transgene inheritance for at least 22 months. The transgenic rate of germ-line transmission was as low as $0.4 \%(2 / 491)$. Hence, while the efficiency of gene transfer on microalgae still requires improvement, we have, nonetheless, observed that increasing the transformation rate of the parental generation also increases the potential for the screening of additional good clones from succeeding generations.

\subsection{RFP expression}

Interestingly, when we cultured the microalgal transformants on agar plate for 60 days, we observed that surrounding of colonies of both stable-line transformants, 0829A and 0829B, showed a predominant red fluorescence signal under fluorescence microscopy (Fig. 4A and D). After analyses of DNA, RNA and protein, we confirmed that these two microalgal clones harbor expression vector phr-rLFB-Red stably and that the exogenous DNA is transcribed and translated properly by host cells of $N$. oculata. However, we also noticed that the transgenic DNA fragments were abortive in most algal transformants after successive subculture processes and that they did not show a red fluorescence signal around the clone anymore. Therefore, the red signal may be best used as an indicator for screening long-term stable transformants. Nonetheless, we noticed that the transgenic construct we originally designed had a cDNA coding for a 25-amino-acid LFB in $\mathrm{N}$ terminus fused with an RFP, indicating that the signal peptide was not included. Thus, we hypothesize that the appearance of orange color under visible light surrounding the transgenic colonies might result from the green color of chlorophyll of the oldest cells of $N$. oculata that have been dead and lysed mixes with the red color of DsRed.

\subsection{Exogenous protein expression}

After treating the transgenic microalgal line $0829 \mathrm{~A}$ at $42{ }^{\circ} \mathrm{C}$ for $16 \mathrm{~h}$, the peptide band with a molecular mass of about $100 \mathrm{kDa}$, which was shown on the SDS-PAGE analysis, was absent in the proteins extracted from the wild type (Fig. 6A). This 100kDa-protein band was positive for immunological detection when we analyzed by western blotting using mouse monoclonal antibody against DsRed (Fig. 6B). In theory, the molecular mass of
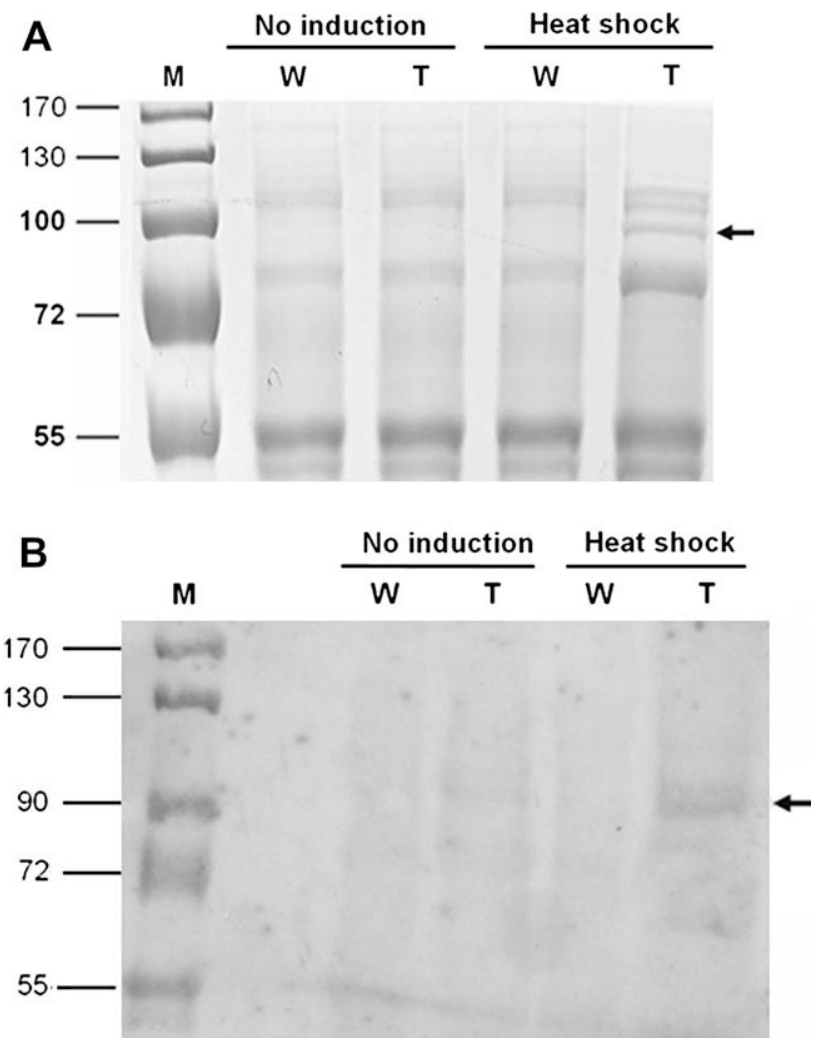

Fig. 6. Protein and western blot analyses of microalgae. After $50 \mathrm{ml}$ of wild type (W) and transgenic $(\mathrm{T})$ microalgae $\left(1 \times 10^{7} \mathrm{cells} \mathrm{m}^{-1}\right)$ were treated at $42{ }^{\circ} \mathrm{C}$ for $16 \mathrm{~h}$, their total proteins were extracted and analyzed by SDS-polyacrylamide gel electrophoresis on a $12 \%$ gel (A). The gel was transferred into nitrocellulose membrane and reacted with monoclonal antiserum against DsRed (B). Arrow indicates the tetramer of recombinant fusion protein LFB-DsRed produced by transgenic microalga. 


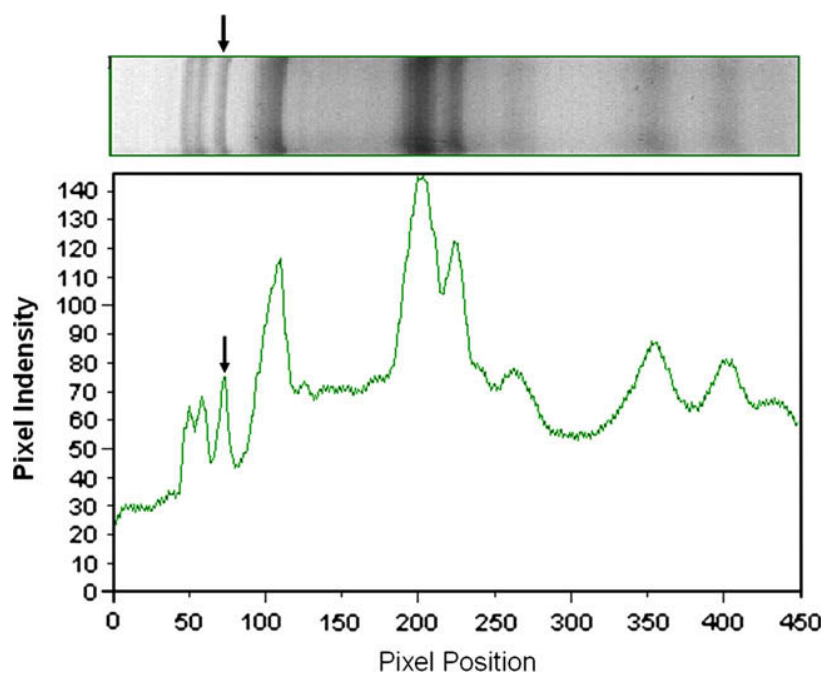

Fig. 7. Quantitative analysis of proteins produced by transgenic microalga. After the transgenic microalga $0829 \mathrm{~A}$ was treated at $42^{\circ} \mathrm{C}$ for $16 \mathrm{~h}$, the total proteins were extracted and analyzed by SDS-PAGE (upper panel). The protein profile was then analyzed by the TotalLab computer program (lower panel). Arrows indicate the recombinant protein LFB-DsRed band and peak produced by transgenic microalga. This exogenous protein was $4.27 \%$ of total soluble proteins.

a monomer of phr-rLFB-Red should be $29.2 \mathrm{kDa}$. Therefore, we need to explain this opposing trend in a way that satisfies our conclusion that the $100-\mathrm{kDa}$ protein is the recombinant protein LFB-DsRed produced by the transgenic microalga we generated. By way of illustration, DsRed in the fusion protein is produced by the expression vector pDsRed 2-1, which is the derivates of pDsRed2. As Clontech reported in Clontechniques (July 2003), the DsRed produced by the expression vector either pDsRed2 or DsRedExpress is formed in a tetramer. And, this DsRed tetramer is hard to display a monomer type, even in the denaturing SDS-PAGE [36]. Because of its un-denatured globular structure, this tetramer is then be located at a position of around $89 \mathrm{kDa}$ on SDS-PAGE, even though the molecular mass of this tetramer would otherwise be $104 \mathrm{kDa}$. Meanwhile, since each monomer of LFB is $3.254 \mathrm{kDa}$, the molecular mass of fusion protein LFB-DsRed produced by transgenic microalgae is $117 \mathrm{kDa}$. It is therefore reasonable that the position of LFB-DsRed located on the SDS-PAGE should be around $100.12 \mathrm{kDa}$, which is positive for western blot analysis using antiDsRed antiserum. Hence, we conclude that the 100-kDa protein is the recombinant protein LFB-DsRed produced by transgenic microalga we generated.

\subsection{Promoter strength}

Based on the quantitative analysis of SDS-PAGE (Fig. 6A), a computer program called TotalLab showed that the transgenic microalgal line 0829A expresses exogenous LFB-DsRed protein at around $4.27 \%$ of total soluble protein after heat shock at $42{ }^{\circ} \mathrm{C}$ for $16 \mathrm{~h}$ (Fig. 7). When comparing the expression level of the same expression vector in the original organism (C. reinhardtii), which is only $\sim 1 \%$ of total soluble protein [19], the expression level generated by the transgenic $N$. oculata we screened in this study was found to be four times greater, which is an unexpected but significant finding. To account for this result, we reasoned that (1) the transgenic microalgal line 0829A has a high expression level and is a stable transformant, (2) the time we treated transgenic $N$. oculata was on the order of eightfold longer than what was reported in $C$. reinhardtii [19], or (3) the exogenous protein could be expressed more stably and efficiently in $N$. oculata than in $C$. reinhardtii. Whatever the reason, when we compare our results with the expression levels driven by other promoters, we can easily demonstrate that the expression level of transgenic microalga is much higher. For example, GUS by rbcL in C. reinhardtii [37], antibody against herpes simplex virus glycoprotein $\mathrm{D}$ by rbcL in $C$. reinhardtii [12], mucosal vaccine against foot-and-mouth disease virus by chlL in C. reinhardtii [38] and GUS by fucoxanthin chlorophyll-binding proteins promoter in diatom Phaeodactylum tricornutum [39] are $0.01,0.5,3$ and $0.7 \%$ of total soluble proteins, respectively, and all are lower in expression level than our transgenic $N$. oculata.

\subsection{Bactericidal efficacy}

Based on the in vitro plaque assay and in vivo (oral-in-tube) experiments in this study, we clearly demonstrated that the LBF released from transgenic microalgal line 0892A is capable of killing E. coli (data not shown), as well as the aquaculture pathogen
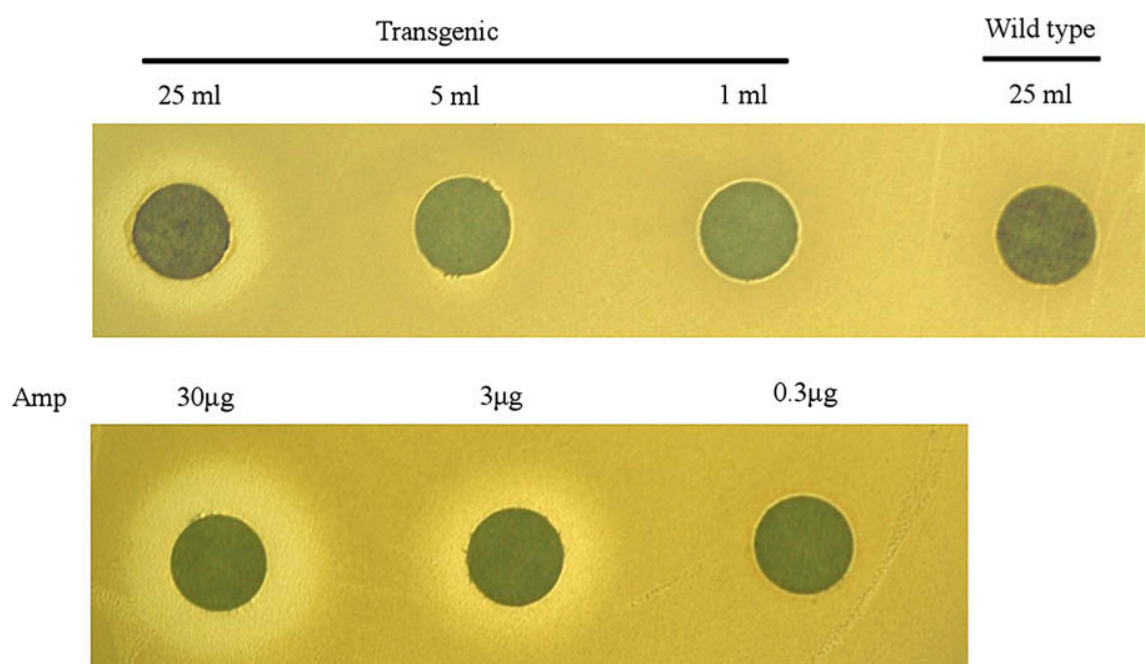

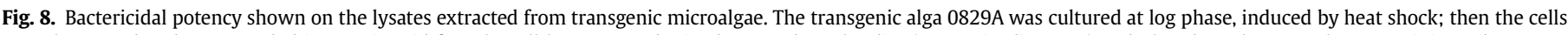

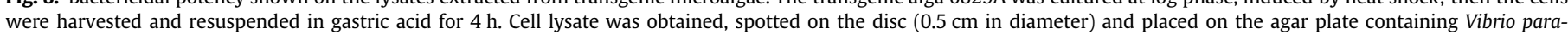

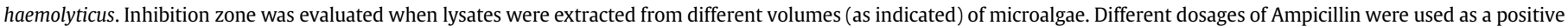
control for calculating the potency of functional domain of LFB produced by transgenic microalgae after gastric juice treatment. 
Table 1

The survival rate of medaka fish fed with algae after $V$. parahaemolyticus infection

\begin{tabular}{lllll}
\hline Injection & Infection & & & \\
\cline { 2 - 5 } & Dsw & Microalgae & & \\
\cline { 3 - 5 } & & Wild type & Transgenic & \\
\cline { 3 - 5 } & & & Low & High \\
\hline Dsw & $95 \pm 7.1$ & $95 \pm 7.1$ & $95 \pm 7.1$ & 100 \\
Cont & 90 & 100 & 100 & $95 \pm 7.1$ \\
VP-L & $15 \pm 7.1$ & 10 & $65 \pm 21.2$ & $95 \pm 7.1$ \\
VP-H & 0 & $5 \pm 7.1$ & 70 & $85 \pm 7.1$ \\
\hline
\end{tabular}

Medaka fish were fed orally-in-tube with microalga $N$. oculata, and $6 \mathrm{~h}$ later were orally-in-tube injected $V$. parahaemolyticus. The survival rate of medaka was calculated $24 \mathrm{~h}$ after $V$. parahaemolyticus infection on the basis of examining 10 medaka fish. Dsw: $10 \mu$ distilled seawater; Cont: high dosage of dead (boiled for $30 \mathrm{~min}$ ) $\mathrm{V}$. parahaemolyticus $\left(1 \times 10^{5}\right.$ cells per fish) which served as negative control; VP-L: low dosage of living $V$. parahaemolyticus $\left(1 \times 10^{4}\right.$ cells per fish); VP-H: high dosage of living $V$. parahaemolyticus $\left(1 \times 10^{5}\right.$ cells per fish); wild type: wild-type $N$. oculata $\left(1 \times 10^{8}\right.$ cells per fish); TL: low dosage of transgenic $N$. oculata $\left(1 \times 10^{6}\right.$ cells per fish); and TH: high dosage of transgenic $N$. oculata $\left(1 \times 10^{8}\right.$ cells per fish). The data were presented by the average of two independent trials.

V. parahaemolyticus. To avoid previously co-habitating Vibrio, we used medaka, a small freshwater fish, as an experimental animal because medaka can adapt to and survive in seawater. We were able achieve this adaptation from freshwater to seawater within a period of five days, after which we began induction of $V$. parahaemolyticus infection. This marine Vibrio was absent in the medaka before adaptation. A dosage of $1 \times 10^{5}$ cells of $V$. parahaemolyticus is lethally infectious for one medaka fish. The minimum time required for the protection of pathogenic infection in medaka intestine is $6 \mathrm{~h}$ after having been fed with transgenic algae. A period of less than $6 \mathrm{~h}$ reduces the protective effect of LFB released from transgenic microalga. In addition to time dependency, protection of pathogen infection by the LFB-containing microalga is also dose-dependent: the higher the bacterial count of $V$. parahaemolyticus, the lower the protection of LFB against Vibrio infection.

\subsection{Biological safety}

Using antibiotic selection is the most common strategy for screening the putative transformants of plant cells. However, this strategy has potential risks in terms of environmental impact and food safety. Moreover, many antibiotics become less efficacious in seawater, which, in turn, requires more antibiotic potency if algae are cultured. Therefore, instead of antibiotics, we used DsRed as a selection marker, which originates from coral reef and belongs to one of the organisms in the ocean food chain. It is not necessary to use antibiotics as a selective pressure during culturing the transformants which contain the plasmid encoding an antibioticresistant marker gene. In our study, after we cultured the microalga on the solid-phase agar plate for a long period of time, we selected colonies which showed a predominant red fluorescence signal and continued to subculture them several times in a liquid medium that was not more than $250 \mathrm{ml}$ per clone.

Unlike the genetically modified fish which contain exogenous genes in their genome, fish fed with genetically modified microalgae do not contain the transgenic gene after they have been cleaved in the digestive tract. Therefore, several months or years after having been fed transgenic microalgae, it is extremely unlikely that these fish will still harbor exogenous genes. Notwithstanding this, we believe it is more biologically safe for humans to consume non-transgenic fish which have been fed with microalgae for only a temporary period under controlled aquaculture conditions. There are some additional biosafety concerns to be raised. First, since microalgae are asexually productive organisms, they lack gametes, a fact which may greatly reduce the risk of horizontal transmission of transgenes in the environment. Second, the fact that recycled and closed water systems are popular in the microalgae industry almost guarantees that transgenic $N$. oculata will not be released into the environment. Finally, the transgenic microalgae can be killed before use by heat treatment. In the alternative, dehydration of microalgae can also protect the environment from contamination. In any case, because there are still potential environmental risks involved with the application of transgenic algae, we recommend that licensing be mandated as a fundamental requirement in regulating the manufacture and use of this bioproduct.

\section{Acknowledgements}

We thank Dr. H.M. Su, Biotechnology Division of the Fisheries Research Institute, Tungkang, Taiwan, for providing the $N$. oculata strain. We also thank Prof. Schroda, Institut Für Biolie III, Universität Freiburg, Germany, for the kind gift of the pCB740 plasmid. We also thank Prof. Y.L. Song and Prof. S.C. Chi, Institute of Zoology, National Taiwan University, for helping to provide the Vibrio and to design the infection experiment. This work was partially supported by the National Science Council.

\section{References}

[1] Bellamy W, Takase M, Yamauchi K, Wakabayashi H, Kawase K, Tomita M Identification of the bactericidal domain of lactoferrin. Biochim Biophys Acta 1992;1121:130-6

[2] Yamauchi K, Tomita M, Giehl T, Ellison R. Antibacterial activity of lactoferrin and a pepsin-derived lactoferrin peptide fragment. Infect Immun 1993;719-28.

[3] Bellamy W, Takase M, Wakabayashi H, Kawase K, Tomita M. Antibacterial spectrum of lactoferricin $B$, a potent bactericidal peptide derived from the N-terminal region of bovine lactoferrin. J Appl Bacteriol 1992;73:472-9.

[4] Bellamy W, Wakabayashi H, Takase M, Kawase K, Shimamura S, Tomita M. Killing of Candida albicans by lactoferricin B, a potent antimicrobial peptide derived from the N-terminal region of bovine lactoferrin. Med Microbiol Immunol 1993;182:97-105.

[5] Omata Y, Stake M, Maeda R, Saito A, Shimazaki K, Uzuka Y, et al. Reduction of the infectivity of Toxoplasma gondii and Eimeria stiedai sporozoites by treatment with bovine lactoferricin. J Vet Med Sci 2001;63:187-90.

[6] Turchany JM, Aley SB, Gillin FD. Giardicidal activity of lactoferrin and Nterminal peptides. Infect Immunol 1995;63:4550-2.

[7] Tanaka T, Omata Y, Saito A, Shimazaki K, Yamauchi K, Takase M. Toxoplasma gondii: parasiticidal effects of bovine lactoferricin against parasites. Exp Parasitol 1995;81:614-7.

[8] Biase A, Pietrantoni A, Tinari A, Siciliano R, Valenti P, Antonini G, et al Heparin-interacting sites of bovine lactoferrin are involved in anti-adenovirus activity. J Med Virol 2003;69:495-502.

[9] McCann K, Lee A, Wan J, Roginski H, Coventry M. The effect of bovine lactoferrin and lactoferricin $\mathrm{B}$ on the ability of feline calicivirus (a norovirus surrogate) and poliovirus to infect cell cultures. Appl Microbiol 2003;95: 1026-33.

[10] Andersen J, Jenssen H, Gutteberg TJ. Lactoferrin and lactoferricin inhibit Herpes simplex, 1 and 2 infection and exhibit synergy when combined with acyclovir. Antiviral Res 2003;58:209-15.

[11] Tomita M, Wakabayashi H, Yamauchi K, Teraguchi S, Hayasawa H. Bovine lactoferrin and lactoferricin derived from milk: production and applications. Biochem Cell Biol 2002;80:109-12.

[12] Mayfield SP, Franklin SE, Lerner RA. Expression and assembly of a fully active antibody in algae. Proc Natl Acad Sci U S A 2003;100:438-42.

[13] Griesbeck C, Kobl I, Heitzer M. Chlamydomonas reinhardtii: a protein expression system for pharmaceutical and biotechnological proteins. Mol Biotechnol 2006;34:213-23.

[14] Hibberd DJ, Margulis L, Corliss JO, Melkonian M, Chapman DJ. Handbook of Protoctista. Boston: Jones and Bartlett Publishing; 1990.

[15] Sukenik A. Production of EPA by marine eustigmatophyte Nannochloropsis. In: Cohen E, editor. Chemicals from microalgae. London: Taylor \& Francis Publishing Inc; 1999. p. 41-56.

[16] Lubzens E, Gibson O, Zmora O, Sukenik A. Potential advantages of frozen algae (Nannochloropsis sp.) for rotifer (Brachionus plicatilis) culture. Aquaculture 1995;133:295-309.

[17] Poncet JM, Veron B. Cryopreservation of the unicellular marine alga, Nannochloropsis oculata. Biotechnol Lett 2003;25:2017-22.

[18] Gwo JC, Chiu JY, Chou CC, Cheng HY. Cryopreservation of a marine microalga Nannochloropsis oculata (Eustigmatophyceae). Cryobiology 2005;50:338-43.

[19] Schroda M, Blocker D, Beck CF. The HSP70A promoter as a tool for the improved expression of transgenes in Chlamydomonas. Plant J 2000;21:121-31. 
[20] Naya H, Romero H, Carels N, Zavala A, Musto H. Translational selection shapes codon usage in the GC-rich genome of Chlamydomonas reinhardtii. FEBS Lett 2001;501:127-30.

[21] Guillard RRL. Culture of phytoplankton for feeding marine invertebrates. In: Smith WL, Chanley MH, editors. Culture of marine invertebrate animals. New York: Plenum Press Inc; 1975. p. 26-60.

[22] Atkins TW. Biodegradation of poly(ethylene adipate) microcapsules in physiological media. Biomaterials 1998;19:61-7.

[23] Chen Y, Wang Y, Sun Y, Zhang L, Li W. Highly efficient expression of rabbit neutrophil peptide-1 gene in Chlorella ellipsoidea cells. Curr Genet 2001;39:365-70.

[24] Dawson HN, Burlingame R, Cannons AC. Stable transformation of Chlorella: rescue of nitrate reductase-deficient mutants with the nitrate reductase gene. Curr Microbiol 1997;35:356-62.

[25] Hawkins RL, Nakamura M. Expression of human growth hormone by the eukaryotic alga, Chlorella Curr Microbiol 1999·38:335-41.

[26] Franklin S, Ngo B, Efuet E, Mayfield SP. Development of a GFP reporter gene for Chlamydomonas reinhardtii chloroplast. Plant J 2002;30:733-44.

[27] Tsai HJ, Lin KL, Chen TT. Molecular cloning and expression of yellowfin porgy (Acanthopagrus latus Houttuyn) growth hormone cDNA. Comp Biochem Physiol 1993;104B:803-10.

[28] Ha KK, Chun DS, Kim JS, Yun CH, Lee JH, Hong SK, et al. Expression of the cationic antimicrobial peptide lactoferricin fused with the anionic peptide in Escherichia coli. Appl Microbiol Biotechnol 2006;72:330-8.

[29] Feng XJ, Wang JH, Shan AS, Teng D, Yang YL, Yao Y, et al. Fusion expression of bovine lactoferricin in Escherichia coli. Protein Expr Purif 2007;47:110-7.
[30] Wang H, Zhao X, Lu F. Heterologous expression of bovine lactoferricin in Pichia methanolica. Biochemistry (Mosc) 2007;72:640-3.

[31] Samuelsen R, Haukland HH, Barbara CK, Christof E, Richard AP, Hilde U, et al. Staphylococcus aureus small colony variants are resistant to the antimicrobial peptide lactoferricin B. J Antimicrob Chemother 2005;56:1126-9.

[32] Kuwata H, Yip T, Tomita M, Hutchens TW. Direct evidence of the generation in human stomach of an antimicrobial peptide domain (lactoferricin) from ingested lactoferrin. Biochim Biophys Acta 1998;1429:129-41.

[33] Kindle KL. High-frequency nuclear transformation of Chlamydomonas reinhardtii. Proc Natl Acad Sci U S A 1990;87:1228-32.

[34] Debuchy R, Purton S, Rochaix JD. The argininosuccinate lyase gene of Chlamydomonas reinhardtii: an important tool for nuclear transformation and for correlating the genetic and molecular maps of the ARG7 locus. EMBO J 1989;8:2803-9.

[35] Liliana R, Graziella CZ, Laura B, Giovanna R, Mario RT. Growth medium recycling in Nannochloropsis sp. mass cultivation. Biomol Eng 2003;20:243-8.

[36] Rahimi Y, Shrestha S, Deo SK. Metal affinity based purification of red fluorescent protein. Chromatographia 2007;65:429-33.

[37] Ishikura K, Tataoka Y, Kata K, Sekine M, Yoshida K, Shinmyo A. Expression of a foreign gene in Chlamydomonas reinhardtii chloroplast. J Biosci Bioeng 1999;87:307-34.

[38] Sun M, Qian K, Su N, Chang H, Liu J, Chen G. Foot-and-mouth disease virus VP1 protein fused with cholera toxin B subunit expressed in Chlamydomonas reinhardtii chloroplast. Biotechnol Lett 2003;25:1087-92.

[39] Zaslavskaia LA, Lippmeier JC, Kroth PG, Grossman AR, Apt KE. Transformation of the diatom Phaeodactylum tricornutum (Bacillariophyceae) with a variety of selectable marker and reporter genes. J Phycol 2000;36:379-86. 